研究

\title{
Evaluation of Pitting Corrosion Behavior of Sintered SUS444 Stainless Steel in $\mathrm{MgCl}_{2}$ Solution
}

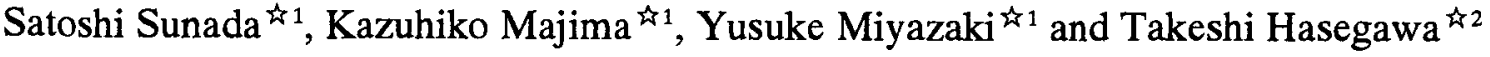 \\ ${ }^{4}$ Department of Materials Systems Engineering and Life Science, Faculty of Engineering, Toyama University, 3190 Gofuku, Toyama $930-8555$. \\ ${ }^{2}$ Metal Powder Division, Daido Steel Co.,Ltd., 10 Ryugu-cho Minato-ku, Nagoya 455-0022.
}

Received February 25, 2004

\begin{abstract}
SYNOPSIS
Three kinds of sintered SUS444 stainless steels (P/M stainless steels) whose porosity ratios were 6.9,9.1 and 13.3 were used in this experiment, and their pitting corrosion behaviors in $\mathrm{MgCl}_{2}$ solution were investigated by means of electrochemical measurement and SEM observation compared with normal type SUS444 stainless steel (I/M stainless steel) produced by conventional method. The pitting corrosion resistance of $P / M$ stainless steel decreased with the increasing porosity ratio, and it was lower compared with the I/M stainless steel. The potential of pitting corrosion decreased with an increase in porosity, and the pitting corrosion rate increased as the anodic potential and the porosity ratio increased.
\end{abstract}

KEY WORDS

pitting corrosion, SUS444 steel, porosity ratio, electrochemical measurement, pitting potential

\section{Introduction}

Ferritic stainless steel SUS444, which has superior corrosion resistance, especially to stress corrosion cracking, is applied to relatively low pressure vessels such as warm or hot water tanks ${ }^{1)}$. Recently, since sintered stainless steels using powder metallurgy process have the advantage of better formability, they have been studied to produce complex shape products without machining or welding.

On the other hand, since passivaion film of the stainless steel surface becomes unstable in the solution containing halogen ions even under the neutral corrosive environment, pitting corrosion which is one type of local corrosion occurs. Because the occurrence of pits increases the surface roughness and they grow to the perpendicular direction to the surface, they sometimes become the through-holes in spite of small weight loss and, as a result, they cause an accidental leakage of the media.

In this study, the quantitative investigation on initiation and growth of the pit using electrochemical measurement and surface and cross sectional observation were carried to clarify the pitting corrosion behavior of sintered SUS444 stainless steel in neutral $\mathrm{MgCl}_{2}$ solution.

\subsection{Experimental material}

\section{Experimental procedures}

Materials used for the experiment were SUS444 stainless steels: one was made by conventionally processed steel and another was sintered one using powder metallurgy process. These compositions are shown in Table 1 and 2 , respectively. Sintered materials were formed by 3 different compacting pressures. Conventionally processed SUS444, marked as I/M material in the figures, was sampled from the cast and wrought commercial plate in $2 \mathrm{~mm}$ thickness, and the plate was cut into a specimen of $12 \mathrm{~mm}$ in width and $60 \mathrm{~mm}$ in length. Sintered SUS444 was produced using water-atomized powder of approximately $60 \times 10^{-6} \mathrm{~mm}$ in average diameter

Table 1 Chemical composition (wt\%) of SUS444 stainless steel.

\begin{tabular}{c|c|c|c|c|c|c|c|c|c|c|c}
\hline \hline $\mathrm{C}$ & $\mathrm{Si}$ & $\mathrm{Mn}$ & $\mathrm{P}$ & $\mathrm{S}$ & $\mathrm{Ni}$ & $\mathrm{Cr}$ & $\mathrm{Mo}$ & $\mathrm{Cu}$ & $\mathrm{Nb}$ & $\mathrm{N}$ & $\mathrm{Ti}$ \\
\hline 0.004 & 0.26 & 0.13 & 0.02 & 0.001 & 0.10 & 18.30 & 1.92 & 0.02 & 0.337 & 0.011 & 0.01 \\
\hline
\end{tabular}


Table 2 Chemical composition (wt\%) of SUS444 stainless steel powder.

\begin{tabular}{c|c|c|c|c|c|c|c|c|c|c|c}
\hline \hline $\mathrm{C}$ & $\mathrm{Si}$ & $\mathrm{Mn}$ & $\mathrm{P}$ & $\mathrm{S}$ & $\mathrm{Ni}$ & $\mathrm{Cr}$ & $\mathrm{Mo}$ & $\mathrm{Cu}$ & $\mathrm{Nb}$ & $\mathrm{N}$ & $\mathrm{O}$ \\
\hline 0.012 & 0.84 & 0.22 & 0.025 & 0.005 & 0.12 & 17.70 & 1.86 & 0.04 & 0.01 & 0.028 & 0.28 \\
\hline
\end{tabular}

made by Daido Special Steel Co. Ltd. The appropriate amount of the powder was compressed to the size of $2.2 \times$ $12 \times 60 \mathrm{~mm}$ at different applied pressures of 392,588 , and $784 \mathrm{Mpa} .1$ mass \% of ACRAWAX was mixed with the powder as a lubricant for compaction. After forming at the room temperature with different pressures, the compressed specimens were dewaxed at $673 \mathrm{~K}$ for $3.6 \mathrm{ks}$ in air and subsequently sintered at $1473 \mathrm{~K}$ for $3.6 \mathrm{ks}$ in vacuum. These specimens are marked as $\mathrm{P} / \mathrm{M}$ material in the figures. For pitting potential measurement, reactive side of the specimen for the electrode was polished with a No. 2000 grit waterproofed abrasive paper followed by ultrasonic rinsing in acetone. Electrodes were made by coating with silicon rubber with uncoated area of $1 \times 10^{-4} \mathrm{~m}^{2}$ for as the exposed surface. 2.2 Test solution

$\mathrm{MgCl}_{2}$ solution concentrations of which were $0.1,0.2$, $0.5,1.0$, and $2.0 \mathrm{kmol} / \mathrm{m}^{3}$ was used in this experiment. Before being used for the experiment, specimens were treated by $0.5 \mathrm{kmol} / \mathrm{m}^{3} \mathrm{MgSO}_{4}$ solution for the formation of the passivation film. Those solutions were adjusted by deionized water whose specific electric conductivity was less than $2.0 \times 10^{-5} \mathrm{~S} \cdot \mathrm{m}$.

\subsection{Measuring apparatus}

Fig. 1 shows the diagram of measuring apparatus for pitting corrosion behavior of SUS444 stainless steels. It consists of thermostatic bath, $\mathrm{H}$-type electrolytic cell with anodic and cathodic chambers of $2 \times 10^{-4} \mathrm{~m}^{3}$ in volume, intermediate cell $\mathrm{Ag}-\mathrm{AgCl}\left(3.33 \mathrm{kmol} / \mathrm{m}^{3} \mathrm{KCl}\right)$ as a reference electrode, potentiostat, coulomb meter and a personal computer for the measurement control. All of the potential values were shown based on the $\mathrm{Ag}-\mathrm{AgCl}$ reference electrode.

\subsection{Pitting potential measurement}

Before pitting potential measurement, specimens were treated in $0.5 \mathrm{kmol} / \mathrm{m}^{3} \mathrm{MgSO}_{4}$ solution of $298 \mathrm{~K}$ for $1.8 \mathrm{ks}$ with the potential of $0.2 \mathrm{~V}$ by potentiostat. As soon after pre-treatment, an anodic polarization curve was measured by potentiodynamic polarization method in $\mathrm{MgCl}_{2}$ solutions with a potential sweeping rate of $\mathrm{dE} / \mathrm{dt}=5 \times 10^{-4} \mathrm{~V} / \mathrm{s}$. Pitting potential, $\mathrm{E}_{\mathrm{pit}}$, was determined using anodic polarization curve: the potential at which anodic current density rapidly increased from the passivation area in which the current density curve are constantly linear. High purity nitrogen gas was introduced for $1.8 \mathrm{ks}$ into the test solution to deoxidize, and the solution surface was covered with the same gas during potential measurement.

2.5 Static potential corrosion test

Static potential test was carried out in order to investigate quantitatively the effect of $\mathrm{MgCl}_{2}$ concentration and potential on the initiation and growth of the pit. First, for the formation of the constant passivation film, specimens were treated in $0.5 \mathrm{kmol} / \mathrm{m}^{3} \mathrm{MgSO}_{4}$ solution at $298 \mathrm{~K}$ for $1.8 \mathrm{ks}$ with the potential of $0.2 \mathrm{~V}$. Potentiostatic measurement was conducted in $\mathrm{MgCl}_{2}$ solution at the constant potentials of $0.257,0.357$, and $0.457 \mathrm{~V}$. During the test, anodic current was recorded until the total current reached $3.0 \times 10^{5} \mathrm{C} / \mathrm{m}^{2}$. Apparent rate constant, $\mathrm{dI} / \mathrm{dt}$, was calculated from the automatically recorded anodic current (I) variation for the pit initiation and growth. The effect of corrosion potential and porosity on $\mathrm{dI} / \mathrm{dt}$ was also discussed by using the experimental results.

2.6 Observation of corroded surface

The number and the diameter of the pit on the surface and the cross sectional area after corrosion test were measured

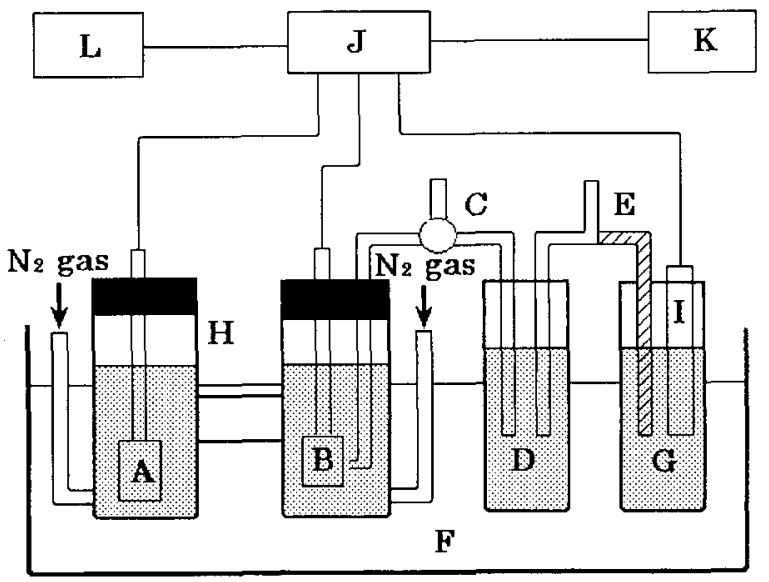

$\mathrm{A}:$ Counter electrode $(\mathrm{Pt}) \quad \mathrm{B}:$ Specimen $\quad \mathrm{C}:$ Bridge $\mathrm{D}$ :Intermediate beaker( $\mathrm{MgCl}_{2}$ solution) $\mathrm{E}:$ Salt bridge F:Water bath G:Saturated potassium chloride solution $\mathrm{H}:$ Electrochemical cell( $\mathrm{MgCl}_{2}$ solution) I:Reference electrode $\mathrm{J}:$ Potentiostat $\mathrm{K}$ :Coulomb meter $\quad \mathrm{L}$ :Computer

Fig.1 Experimental apparatus for pitting corrosion. 
by SEM observation at both initiation and growth stages of the pit.

\section{Results and discussion}

\subsection{Effect of forming pressure on porosity ratio}

As previously mentioned, the one of materials used in this study was produced using SUS444 water atomized powder by compressing them at the pressures of 392, 588 and $784 \mathrm{MPa}$ at the room temperature followed by dewaxing and vacuum sintering. The porosity ratio of sintered stainless steels must be an important factor for corrosion resistance since the oxides originated from powder surface and the impurities may remain in the pore and they may affect corrosion properties due to the formation of micro cells. Therefore, the porosity ratios of sintered SUS444 specimens were measured by the porosity area ratios using computerized image processing of optical microscopy images. According to this measurement, the porosity ratios of the specimens were $13.3 \%, 9.11 \%$, and $6.88 \%$ for the compression pressure of 392,588 , and $784 \mathrm{MPa}$, respectively. For the case of conventionally processed SUS444, porosity ratio was presumed to be $0 \%$.

\subsection{Determination of pitting potential}

Pitting potential is often used for the evaluation of pit generation ${ }^{2}$. Fig. 2 shows a typical polarization curve in $0.2 \mathrm{kmol} / \mathrm{m}^{3} \mathrm{MgCl}_{2}$ solution at $298 \mathrm{~K}$ for the $\mathrm{P} / \mathrm{M}$ specimen compressed at $392 \mathrm{MPa}$. Cathodic current density gradually decreased with increasing potential from $-0.8 \mathrm{~V}$ in cathodic region. Natural electrode potential $\mathrm{E}_{\text {corr }}$ was indicated at

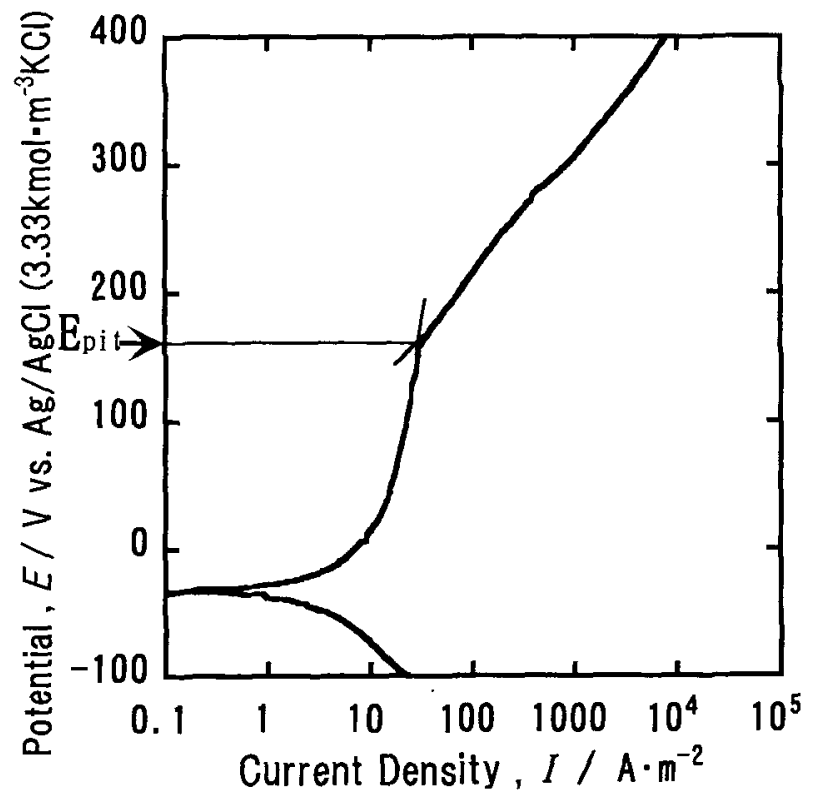

Fig.2 Procedure for determining pitting corrosion in $0.2 \mathrm{kmol} \cdot \mathrm{m}^{-3}$ $\mathrm{MgCl}_{2}$ solution for the specimen compressed at $392 \mathrm{MPa}$.
$-0.035 \mathrm{~V}$. Although anodic current density increased with increasing potential in anodic region over the potential of $-0.035 \mathrm{~V}$, anodic current density abruptly rose at certain potential shown by $E_{\text {corr }}$. This polarization behavior was different from the one for the typical stainless steel, which shows activation-passivation behavior with increasing potential. Pit was observed at specimen surface by increasing current density. By considering these phenomena, that point of abrupt increase was defined as pitting potential.

\subsection{Effect of $\mathrm{MgCl}_{2}$ activity on pitting potential}

Fig. 3 shows the effect of the activity of $\mathrm{Cl}^{-}$ion on pitting potential. Because $\mathrm{Cl}^{-}$was considered to affect on the stability of passivation film in passive region, the activity of $\mathrm{Cl}^{-}$ion which directly affects the pitting potential was chosen as a variable. The activities of $\mathrm{MgCl}_{2}$ test solutions were obtained from the reference ${ }^{3}$.

Wrought SUS444 showed the highest pitting potential under the same $\mathrm{Cl}^{-}$activity conditions. In the case of sintered steels, pitting potential of the one compressed at $784 \mathrm{MPa}$ was the second highest, and it was indicated that pitting potential became low with decreasing the compressing pressure. For each specimen, the pitting potential tended to be lower with increasing the activity of $\mathrm{Cl}^{-}$. Pitting potential of the test specimen indicated linear relationship to the logarithm of $\mathrm{Cl}^{-}$activity, and slope of approximately $-0.17 \mathrm{~V}$ was obtained at 10 times increase of the $\mathrm{Cl}^{-}$activity, however, the reason of this relationship was unclear.

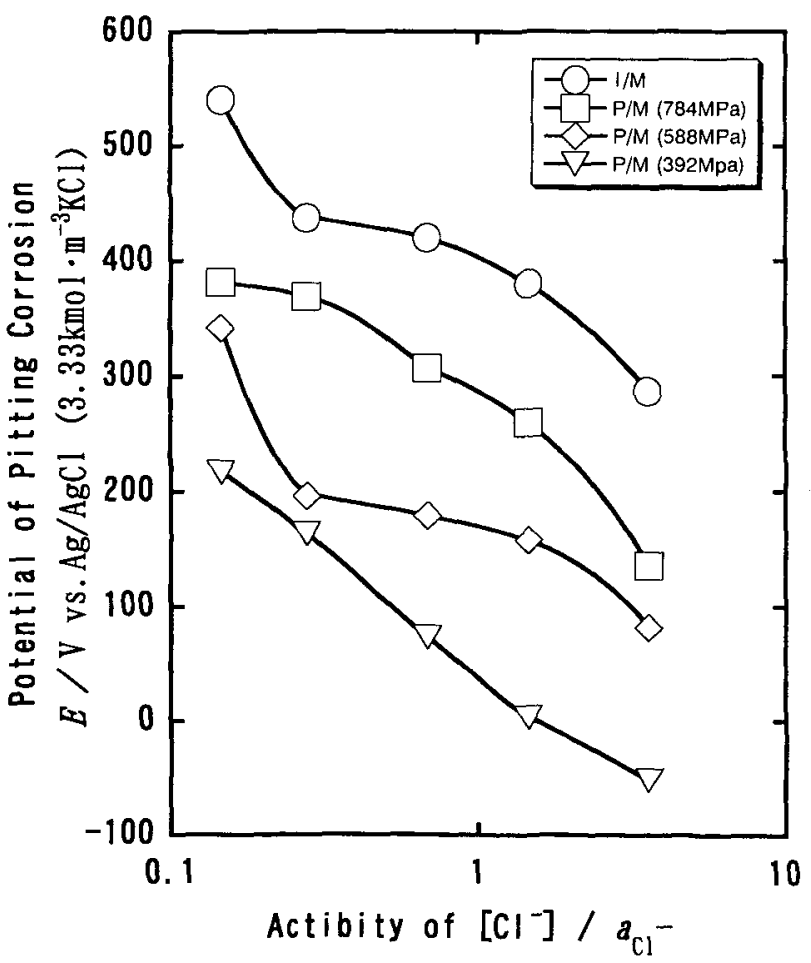

Fig.3 Effect of $\left[\mathrm{a}_{\mathrm{c}}\right]$ on pitting corrosion potential. 
Considering these results, it suggests that an increase of the $\mathrm{Cl}^{-}$activity declines pitting corrosion resistance and causes the initiation of the pit under the investigated corrosive environment.

\subsection{Effect of vacant ratio on pitting potential}

It suggests that the conventionally processed material has better pitting corrosion resistance than sintered one from previous results. Since the sintered steel with higher compressed pressure exhibits better pitting resistance, it is implied that pores in the sintered steel significantly affects the pitting resistance. With thinking this results, the effect of porosity ratio on pitting potential was shown in Fig. 4. As previously mentioned, porosity ratio of conventionally processed steel was considered to be $0 \%$. The results for the $\mathrm{Cl}^{-}$activity of 0.145 and 3.59 were shown as the typical results. It indicated that pitting potential showed the tendency to linearly decrease with the increase of porosity ratio and it decreased approximately $26 \mathrm{mV}$ per $1 \%$ of porosity ratio. It is suggested from the result that pitting corrosion resistance of SUS 444 has closely related to the porosity ratio and the stability of passivation film depends on the amount of pore.

3.5 Effect of porosity ratio on morphology of the pit

Although the effects of $\mathrm{Cl}^{-}$activity and porosity ratio on conventional and sintered SUS444 steels are effective as the evaluation parameters of pitting corrosion resistance of different production processes and the variation of porosity

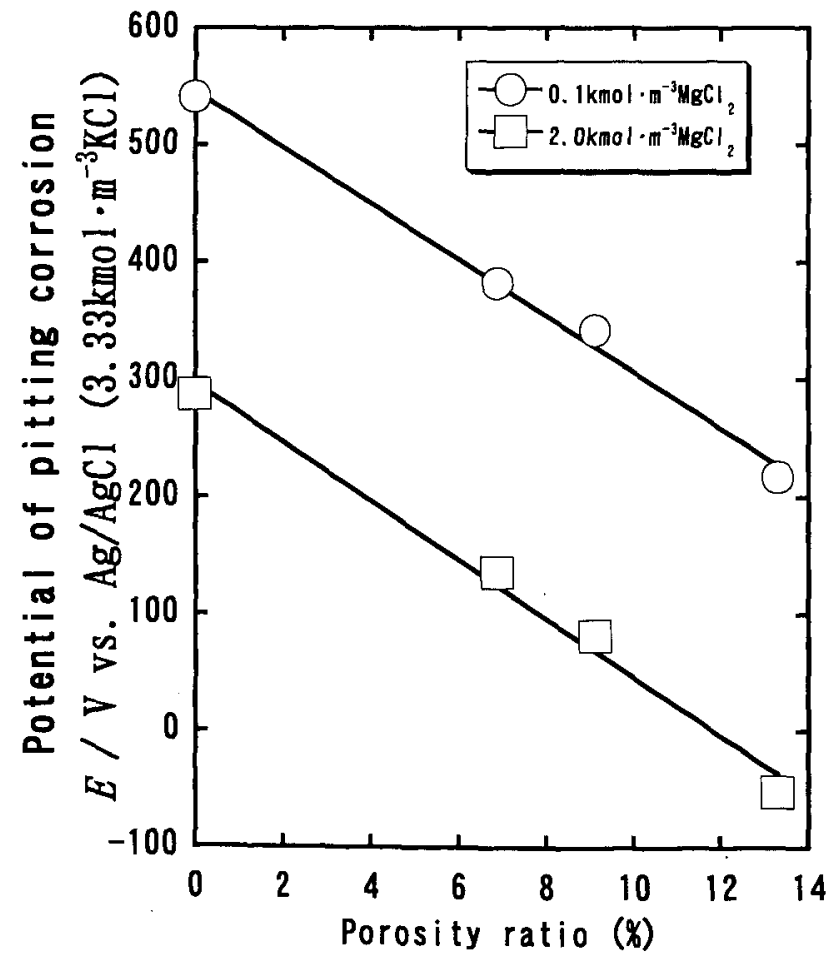

Fig.4 Effect of porosity ratio on pitting corrosion potential. ratio, it is difficult to obtain the information of dynamic behavior for an initiation and growth of the pit. Therefore, the effect of porosity ratio on morphology of the pit was quantitatively examined by using potentiostatical anodic polarization method and SEM observation on the electrode surface.

Fig. 5 shows the SEM photographs after anodic polarization testing at the potential of $0.357 \mathrm{~V}$ for total current of $30 \mathrm{C}$ with a histogram of the diameter of pits at a left side. Many of the observed pits in the specimen of $13.3 \%$ porosity ratio were smaller than $5 \times 10^{-5} \mathrm{~m}$. The number of the pits bigger than $5 \times 10^{-5} \mathrm{~m}$ gradually decreased and no pits over $2.5 \times 10^{-4} \mathrm{~m}$ could not be observed. In the specimen of $9.11 \%$ porosity ratio, the pits of smaller than $5 \times 10^{-5} \mathrm{~m}$ were observed while the number of them was less than half compared with $13.3 \%$ specimen. Moreover, the bigger pits up to $4.5 \times 10^{-4} \mathrm{~m}$ were observed with decreasing the number of the pits compared with $13.3 \%$ specimen. The tendency was emphasized in the specimen of $6.87 \%$ specimen, and only 41 pits were smaller than $5 \times 10^{-5} \mathrm{~m}$. The bigger pits up to $4.0 \times 10^{-4} \mathrm{~m}$ were observed while the number of them were less than that of $9.11 \%$ specimen. In the conventionally processed steel, only 7 pits were smaller than $5 \times 10^{-5} \mathrm{~m}$ and only each one of $3 \times 10^{-4} \mathrm{~m}, 4.5 \times 10^{-4} \mathrm{~m}$, and over $5.0 \times$ $10^{-4} \mathrm{~m}$ were observed.

The shape of the pits relates with the porosity ratio. The number of pits smaller than $5 \times 10^{-5} \mathrm{~m}$ decreased as porosity ratio lowered. Although the number of pits bigger than $5 \times 10^{-5} \mathrm{~m}$ also decreased as porosity ratio lowered, their size distribution shifted to be bigger. The number of pits decreased while their size became bigger in the conventionally processed steel.

Considering these results, the vacancy is considered to act as the initiation of pits. In the case of the specimen with higher porosity ratio, more initiation of pits occurred. In the case of less pore specimen, less number of initiation occurred, but they might grow bigger and deeper.

3.6 Effect of porosity ratio on initiation and growth of pit

Fig. 6 shows typical time-dependent variations of anodic current density at constant potential of $0.357 \mathrm{~V}$ of conventional and differently compressed/sintered SUS444 steels. Variation of the current density divided into 2 regions. The first is incubation region in which the current density is independent on time and indicates nearly 0 and at which nuclear of the pit is generated on the passivation film ${ }^{5}$. In the second region, the current density linearly increases with depending on time, and an initiation and growth of the pit. As indicated in Fig. 6, the region is found at which anodic current density I tends to increase with 


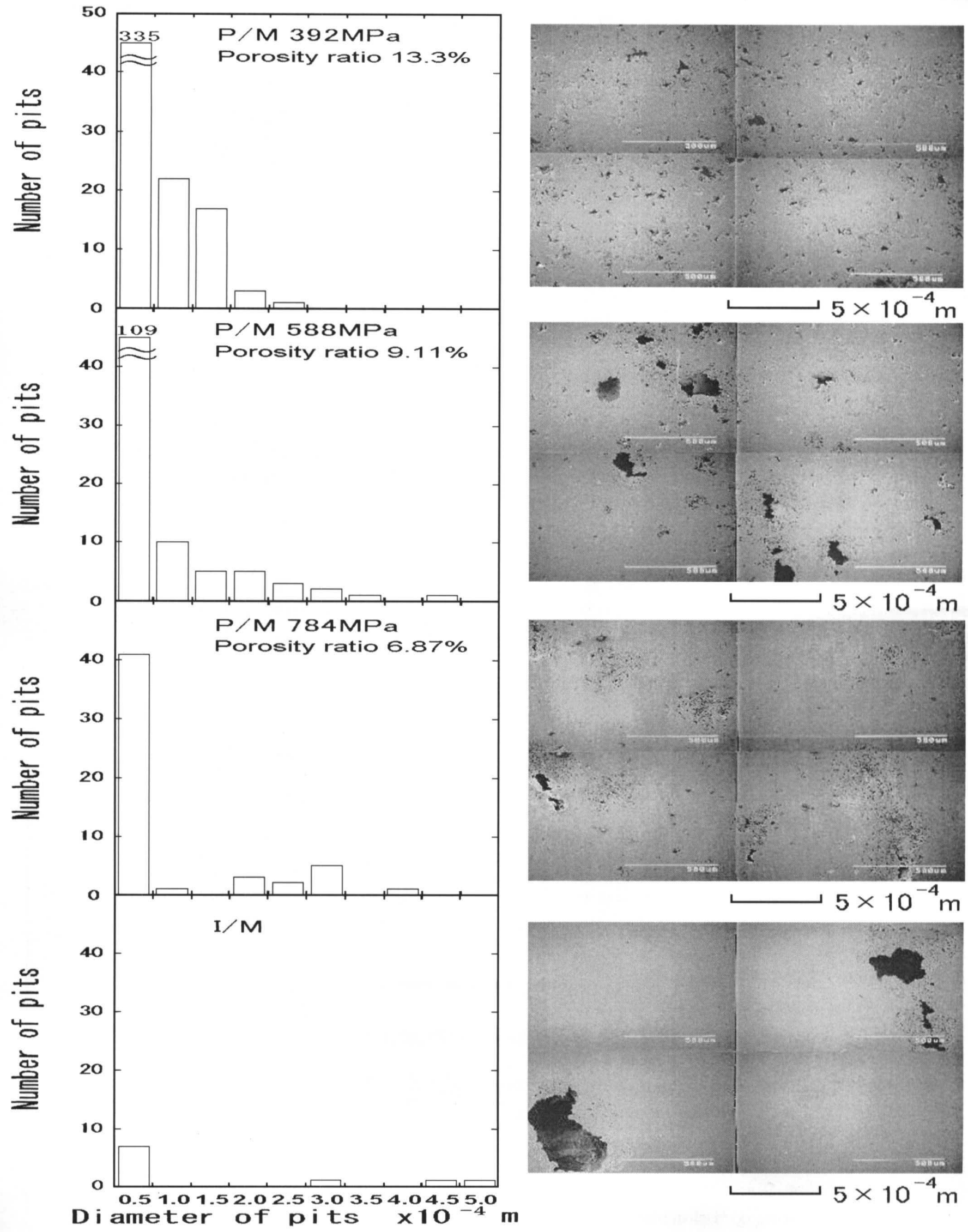

Fig.5 Histogram showing relationship between the number of pits and the diameter of pits, and SEM photographs showing pitting corrosion type corresponding to each specimen. 


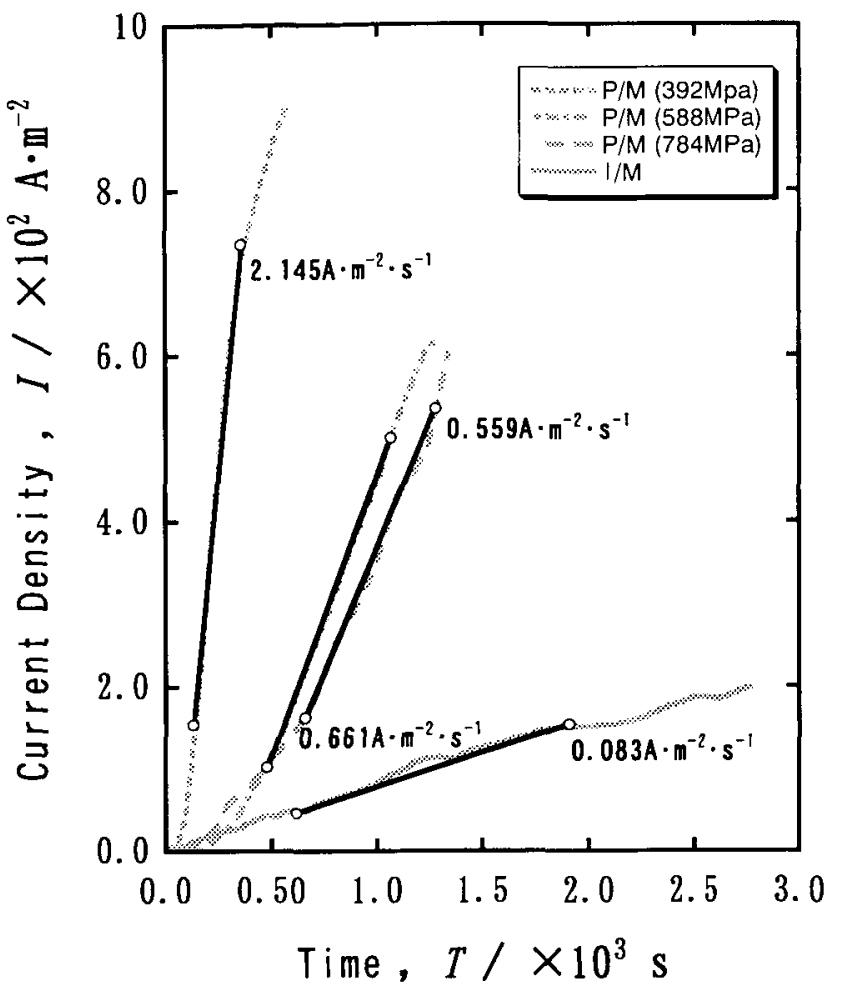

Fig.6 Procedure for determining growth rate of pitting corrosion.

constant slope. Therefore, the effect of an apparent rate $\mathrm{dI} / \mathrm{dt}$ calculated from the slope on the initiation and growth of the pit was examined.

Fig. 7 shows the effect of porosity ratio on the apparent rate $\mathrm{d} / \mathrm{dt}$. The potential used was constant at $0.257 \mathrm{~V}, 0.357 \mathrm{~V}$ and $0.457 \mathrm{~V}$. The apparent rate exponentially increased with increasing porosity ratio, which indicates the pore works as an accelerating factor for the growth of the pit. 3.7 Effect of potential on initiation and growth of pit

The effect of potential on apparent rate was examined to evaluate the quantitative effect of the potential on initiation and growth of pit for conventional and differently compressed/sintered SUS444 steels.

Fig. 8 shows the effect of the potential on apparent rate. The apparent rate increased almost linearly with increasing the potential. The specimen which was formed at $392 \mathrm{MPa}$ and had the largest porosity ratio took the greatest influence of the potential, which suggests that the tiny increase of potential leads to the initiation and growth of the pit.

\section{Summary}

In this study, the pitting corrosion behavior in neutral $\mathrm{MgCl}_{2}$ solution was examined for conventionally processed and sintered SUS444 stainless steels. The main results obtained are as follows.

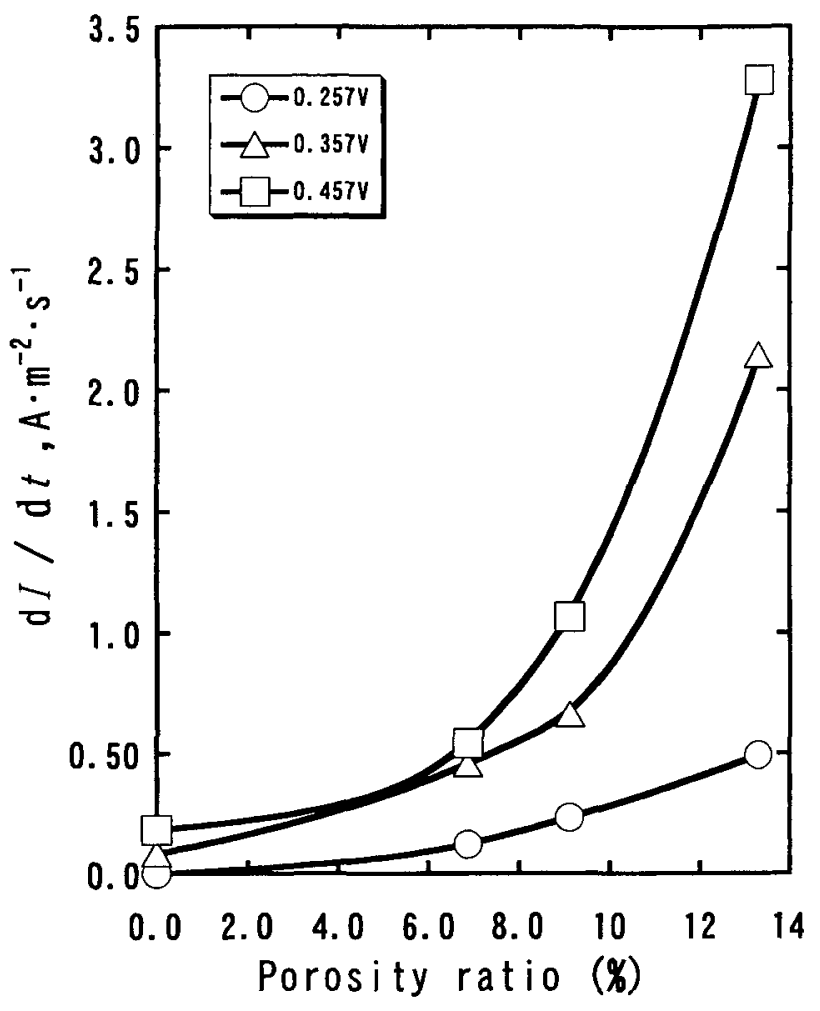

Fig.7 Effect of porosity ratio on growth rate of pitting corrosion for $\mathrm{I} / \mathrm{M}$ and $\mathrm{P} / \mathrm{M}$ specimens.

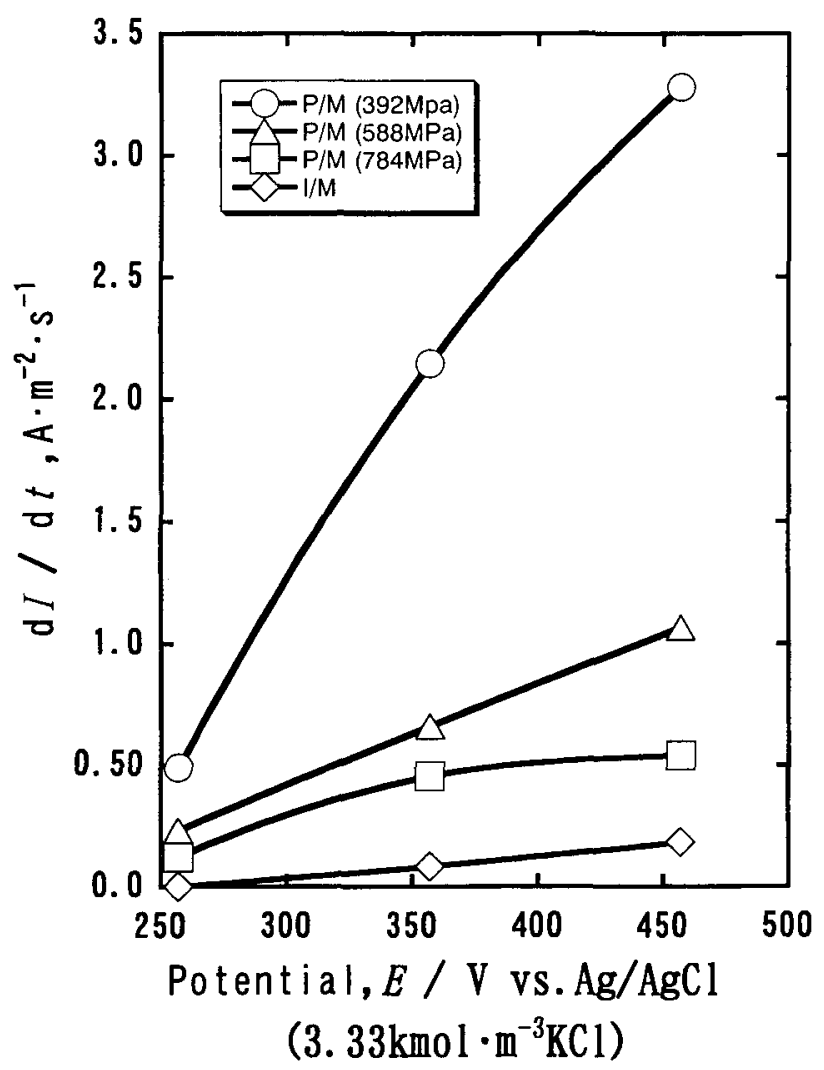

Fig.8 Effect of potential on growth rate for $\mathrm{I} / \mathrm{M}$ and $\mathrm{P} / \mathrm{M}$ specimens. 
(1) The pitting potential of conventional material indicated the highest pitting potential than any other sintered materials. The conventional material has better pitting corrosion resistance.

(2) The pitting potential of in neutral $\mathrm{MgCl}_{2}$ solution decreased almost linearly as porosity ratio increased. The decreasing amount of the potential was $26 \mathrm{mV}$ per $1 \%$ of porosity ratio.

(3) Regarding the effect of potential on the corrosive manner of the pit, more small pits were observed in the specimen with larger porosity ratio while less number but larger diameter pits were observed in the specimen with smaller porosity ratio.

(4) The apparent rate in the stage of the pit initiation and growth exponentially increased as porosity ratio increased.

(5) The apparent rate in the stage of the pit initiation and growth increased almost linearly with potential increase, irrespective of porosity ratio. The specimen which was formed at $392 \mathrm{MPa}$ and had the largest porosity ratio took the greatest influence of the potential, which suggests that the tiny increase of potential leads to the initiation and growth of the pit.

\section{References}

1) Stainless Kyokai: Stainless Binran, Nikkan kogyo shinbunshya, (1995) 540 .

2) B.Baroux: "The Kinetics of Pit Generation", Corrosion Science, 28(1988)969-986.

3) R.G.Bate, B.R.Staples and R.A.Robinson: "Ionic Hydration and Single Ion Activities in Unassociated Chloride at High Ionic Strengths", Analytical Chemistory, 42(1970) 867-871.

4) S.Sunada, H.Maesato, Y.Yokoi, H.Notoya, S.Sanuki and K.Arai: "Effect of Deformation-Induced Martensite on Pitting Corrosion", J. of the Japan Institute of Metal, 54(1990)1078-1086.

5) K.Sugimoto, Y.Sawada and S.Morioka: "Anordic Polarization Behavior of Pure Aluminum and SAP (Sintered Aluminum Powder)", J. of the Japan Institute of Metal, 30(1960)971-978. 